\title{
MODELLING WATER EXCHANGE BETWEEN COASTAL ELONGATED LAGOON AND SEA: INFLUENCE OF THE MORPHOMETRIC CHARACTERISTICS OF CONNECTING CHANNEL ON WATER RENEWAL IN LAGOON
}

\author{
Yurii Tuchkovenko \\ Department of Oceanography and Marine Nature Management ${ }^{l}$ \\ science@odeku.edu.ua \\ Oksana Tuchkovenko \\ Department of Water Bioresources and Aquaculture ${ }^{l}$ \\ oxatuch2017@ukr.net \\ Valeriy Khokhlov \\ Department of Meteorology and Climatology ${ }^{1}$ \\ khokhlovv@odeku.edu.ua
}

${ }^{1}$ Odessa State Environmental University

15 Lvivska str., Odessa, Ukraine, 65016

\begin{abstract}
The north-western part of the Black Sea Ukrainian coast is characterized by the presence of 12 marine lagoons which do not presently have permanent natural connections with the sea. Because of regional climate change, these lagoons have experienced a significant deficit of annual freshwater balance during the last decades and, consequently, an increase in salinity and eutrophication of their waters. One way to stabilize the hydroecological regime of lagoons is to maintain their regular connection with the sea via artificial connecting channels. The deepest and most prolonged Tyligulskyi Liman lagoon is used as an example to determine the morphometric characteristics (width, depth) of the artificial connecting channel which ensures bidirectional water exchange of the lagoon with the sea, i. e. its partial flushing. A numerical hydrodynamic model is used to estimate how the morphometric characteristics of the connecting channel influence the intensity of water exchange between the lagoon and the sea and of water renewal by seawater for the various parts of the lagoon. The dynamics of sea water volume concentration in reference points in the lagoon is used as an indicator of seawater intrusion into the lagoon and their degree of water renewal in its various zones. The proposed methodology could be used for other lagoons of the same type in the north-western part of the Black Sea.
\end{abstract}

Keywords: Water renewal, Modelling, North-Western Black Sea, Tyligulskyi Liman lagoon.

DOI: $10.21303 / 2461-4262.2019 .00979$

\section{Introduction}

Coastal marine lagoons have significant socioeconomic importance because they provide various ecosystem services to satisfy several public needs (tourism, recreation, high fish productivity, possibilities for aquaculture development, etc.) $[1,2]$. The north-western part of the Black Sea Ukrainian coast is characterized by the presence of 16 marine basins of lagoon and estuarine type whose local name is «the limans». At present, twelve of them are separated from the sea by barriers (isthmus or sand-shell spit) with a width from a few hundred meters up to $4 \mathrm{~km} \mathrm{[3].} \mathrm{These} \mathrm{lagoons}$ are formally called «closed» and are occasionally connected with the sea by artificially created open channels or other water-conveying hydrotechnical constructions. Previously, natural breaks could periodically form in their isthmuses. However, with few exceptions, this process has now practically stopped because of the anthropogenic transformation of the majority of the isthmuses.

Some lagoons were formed as a result of flooding of small and medium rivers estuaries by the sea and are presently separated from it by isthmuses. According to Kjerfve [4] they belong to the «choked» type; that is they are elongated perpendicularly to the seacoast and can be connected with the sea only along a relatively small coastal area in the zone of the marine bay-bar. This is the case of the Sasyk, Khadzhybeiskyi, Kuialnytskyi, Dofinovskyi and Tyligulskyi limans. 
In Ukraine, significant changes in climate and water resources have been observed since the end of the 1980s $[5,6]$. On the coastal zone of the north-western part of the Black Sea, these changes include an increase in climate aridity and a corresponding decrease in the influx of freshwaters into the coastal lagoons from their catchment basins. Furthermore, the increase in air temperature and, consequently, evaporation along with the decrease in atmospheric precipitations and freshwater inputs from river runoff cause a significant deficit of the annual freshwater balance in lagoons. In case of prolonged absence of connection with the sea, lagoons show a long-term tendency toward reduction in their water volume accompanied by an increase in water salinity and concentration of nutrients and pollutants. It is therefore necessary to either increase the inflow of freshwater (e. g. via efficient land and water use at the catchment scale) or to ensure the regular connection of lagoons with the sea. This can compensate the water balance deficit of «choked» lagoons and to stabilize their hydroecological regime.

The first option generally requires significant financial expenditures and managing of numerous socioeconomic problems. Moreover, its effectiveness could be lowered by the reduction of natural river discharge as a result of climate change, especially for lagoons with a water volume exceeding by many times the annual runoff of freshwater from the catchment area. Compared with the $60-80$ s of the twentieth century, regional climate changes will reduce the water resources of the Ukrainian southern rivers by $50 \%$ toward the middle of the twenty first century [6]. Maintaining the current level of economic activity in rivers catchment along with predicted climate changes would destroy their water resources. Considering the modern socio-economic conditions in Ukraine, it is therefore more cost effective and practically feasible to stabilize the hydroecological regime of «choked» lagoons by regulating their water exchange with the sea via man-made connecting channels. The optimal morphometric characteristics of such connecting channels must then be determined to ensure maximal influx of seawater and water renewal for each lagoon. A methodological approach similar to that described [7, 8] was used to solve this problem.

The Tyligulskyi Liman lagoon, the deepest and most prolonged «choked» lagoon of the north-western part of the Black Sea [9], was chosen as a representative case study. This lagoon and the territories adjacent to its coast are included into the natural reserve fund of Ukraine, the list of IBA-territories (Important Bird and Biodiversity Area). Also it is in the international list of sites under the Ramsar Convention on Wetlands of International Importance [10, 11]. The peculiar management problems of Tyligulskyi Liman lagoon ecosystem with respect to other European lagoons have been previously discussed $[2,12,13]$.

The aim of the present work is evaluation of how the morphometric characteristics of the connecting channel influence:

- intensity of water exchange between the lagoon and the sea;

- extent of water renewal by seawater in various areas of the lagoon.

\section{Study area}

Tyligulskyi Liman lagoon is located on the Ukrainian coast of the north-western part of the Black Sea coast $\left(46^{\circ} 39.3^{\prime}-47^{\circ} 05.3^{\prime} \mathrm{N}, 30^{\circ} 57.3^{\prime}-31^{\circ} 12.7^{\prime} \mathrm{E}\right.$; Fig. 1). The lagoon was formerly a valley of Tyligul River subsequently flooded by the sea. It has a basin area of $5,420 \mathrm{~km}^{2}$ and receives most of its freshwater inflow (more than $90 \%$ ) from the Tyligul River $\left(16.9 \mathrm{mln} . \mathrm{m}^{3} / \mathrm{year}\right.$ ). The water surface area of the lagoon is $129 \mathrm{mln} . \mathrm{m}^{2}$ and the water volume $693 \mathrm{mln} . \mathrm{m}^{3}$. At present, the lagoon length is $52 \mathrm{~km}$, while the width varies from 0.2 up to $5.4 \mathrm{~km}$. The maximal depth is $22.2 \mathrm{~m}$ in its southern part, whereas the northern part is shallow-watered with depths less then $4 \mathrm{~m}$ and the average depth is $5.4 \mathrm{~m}[10]$.

The liman is separated from the sea by a natural isthmus through which an artificial channel (length $3.3 \mathrm{~km}$, depth $3 \mathrm{~m}$ ) connecting the liman with the sea was built for fishery purposes at the end of the 1950s. Over the years, the southern part of the channel, which is adjacent to the sea, has significantly shallowed because of the sand transport from the seaside. As a result, its depth has reduced to only a few tens of centimeters by the end of the 20 century. In the 21 century, the channel has been functioning irregularly (25-40 days in spring and autumn) after cleaning from the sand of the first hundred meters in its marine part. 
Starting from 2007, the water level of the lagoon has significantly lowered because of a decrease in the flow capacity of the channel and intensive evaporation from the water surface of the lagoon in summer. This decrease was temporally stopped only in 2010 when the channel was open from April to August.

However, cleaning of the marine part of the channel became ineffective by 2015 because of the significant depth reduction along most of its length. A decision to reconstruct the channel was therefore taken because, following the prolonged absence of connection with the sea, the lagoon experienced a long-term tendency of decreasing water volume. As a consequence, the lagoon is shallowing and its water level having lowered by $1.5 \mathrm{~m}$ compared with the sea level during 5 years.

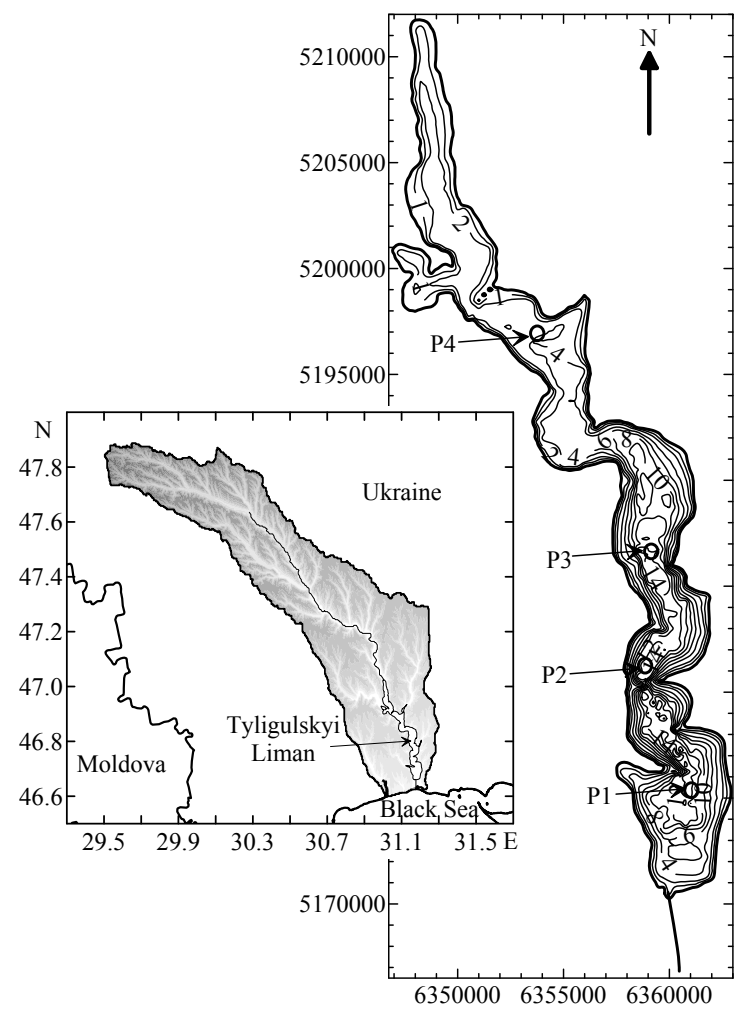

Fig. 1. Geographical settings and bathymetric map (isobaths, meters) of Tyligulskyi Liman lagoon. Points P1-P4 are the reference points for analysis of modelling results. Horizontal coordinate system WGS-84 with the grid marks of $1000 \mathrm{~m}$

At the same time, water salinity increased rapidly along with the concentration of nutrients and pollutants. Given the need to reconstruct the channel, determination of its optimal morphometric characteristics to ensure the maximal water exchange between the lagoon and the sea has become of interest.

\section{Method}

The 3D numerical non-stationary hydrothermodynamical MECCA model (Model for Estuarine and Coastal Circulation Assessment $[14,15]$ ) was applied. This model allows calculating water dynamics and distribution of an admixture in marine basins that have areas with smaller (subgrid) size than the step of the computational grid in one of the horizontal directions (for example a connecting channel). The description of the model equations, parameterizations and boundary conditions in the version adapted for Tyligulskyi Liman lagoon is given in [16]. The lowering of the water level in the liman, due to the difference of daily balance between atmospheric precipitation and evaporation, was taken into account. The evaporation rate $E$ (in $\mathrm{mm}$ per day) from lagoon's water surface is calculated using the formula GHI [17] with consideration of the adjustment factor $K_{s}$ that accounts for the influence of salinity [18] 


$$
E=0.14(1+0.72 W)\left(e_{0}-e_{a}\right) K_{s}
$$

where $W$ is the wind speed; $e_{o}$ is the saturated vapour pressure calculated according to water temperature of the surface layer; $e_{a}$ is the actual vapour pressure calculated from observed values of temperature and relative air humidity;

$$
K_{s}=0.75+0.25 \exp \left(-0.065 S_{o}\right)
$$

For the simulation, the water area of the lagoon (Fig. 1) together with the connecting channel was covered by a horizontal computational grid of $41 \times 107$ points with a step of $400 \mathrm{~m}$. The ten computational levels were used in vertical $\sigma$-coordinate system. The time integration step of the model equations was $3 \mathrm{sec}$.

The model was adapted to the conditions of Tyligulskyi Liman and was tested in the framework of the FP7 project «Integrated water resources and coastal zone management in European lagoons in the context of climate change» [19]. Fig. 2, 3 show some results of model verification, which confirm compliance of the model results with observations in 2010.

\section{Conception and modelling scenarios}

During functioning of the connecting channel, the direction and intensity of water exchange with the sea are determined by the morphological characteristics of the channel (width, depth) and by wind-induced, short-term fluctuations of the sea level.

An admixture of neutral buoyancy was used as a tracer of seawater intrusion into the lagoon and of the corresponding degree of water renewal in different areas of the lagoon. Its concentration was assumed to be equal to 100 arbitrary units in seawater and, initially, to zero in the lagoon. Under this assumption, the dynamics of concentration of the conservative admixture at each point in the space within the computational region of the lagoon corresponds to the sea water volume concentration represented as percentage. For any computational point, attainment of the maximum value of 100 arbitrary units will correspond to total water renewal as a result of seawater inflow. The theoretical aspects of this methodical approach were expounded by [8].

Modelling of seawater intrusion into the lagoon was carried out for the hydrometeorological conditions observed in 2010, when the «sea-lagoon» connecting channel was open from the last ten days of April until the middle of August. This period was the most prolonged one during the last decades. The data from the coastal hydrometeorological station of Port Yuzhniy $\left(46^{\circ} 36.07^{\prime}\right.$ N, $\left.31^{\circ} 01.25^{\prime} \mathrm{E}\right)$ with the 6-hour time step were used to assign the variability of wind direction and speed, air temperature and sea level. The average decadal values from that station were used to assign the variability of salinity and temperature of seawater.

The initial water levels in the sea and in the lagoon were taken to be equal to minus 0.15 and minus 0.4 meters, respectively, in the Baltic system (mBS). The initial vertical distribution of water temperature and salinity in the lagoon was assigned based on observational data and was assumed to be horizontally homogeneous. The above mentioned information was used to define the boundary conditions of model equations during integration in time. The formation of horizontally non-homogenous spatial distribution of temperature and salinity fields occurs as a result of the following processes:

a) different intensity of water heating and salinization (caused by evaporation) in shallowand deep-watered parts of the lagoon;

b) vertical turbulent mixing of the warm superficial and cold near-bottom waters in the deep hollows in the southern and central parts of the lagoon;

c) inflow of freshwater and seawater (with lower salinity than in the lagoon) into the lagoon via the Tyligul River and the connecting channel, respectively.

Scenario calculations were carried out for the following sets of morphometric characteristics of the rectangular section of the channel for a sea level of $-0.15 \mathrm{mBS}$ : 
1) depth of the connecting channel $H_{k}=0.5 \mathrm{~m}$, minimal width $d=25 \mathrm{~m}$ (characteristics during 2010-2016);

2) deepening of the channel up to $H_{k}=1.0 \mathrm{~m}$, at $d=20 \mathrm{~m}$;

3) deepening of the channel up to $H_{k}=2.0 \mathrm{~m}$, at $d=20 \mathrm{~m}$;

4) deepening of the channel up to $H_{k}=2.4 \mathrm{~m}$, at $d=20 \mathrm{~m}$;

5) deepening of the channel up to $H_{k}=2.0 \mathrm{~m}$ and widening up to $d=50 \mathrm{~m}$.

\section{Results}

Modelling results for the variability of water flow rate in the connecting channel are shown in Fig. 2 for the different morphometric characteristics. As can see, the water flow in the channel has a unidirectional character - from the sea into the lagoon - for the depth and width of the channel before beginning of its reconstruction (set 1). Deepening of the shallow water zones of the channel up to $H_{k}=1.0 \mathrm{~m}$ (set 2) increases the water flow rate in the channel, and the water inflow from the sea into the lagoon is still dominant. For a channel's deepening up to $H_{k}=2.0 \mathrm{~m}$ (set 3), water exchange acquires a bidirectional character; i. e. both influx of seawater into the lagoon and water outflow from the lagoon into the sea take place. This bidirectional character is resulted from the wind-induced fluctuations of water level in the sea and the lagoon. Comparison of Sets 4 and 5 shows that further deepening of the channel up to $H_{k}=2.4 \mathrm{~m}$, at a constant width $d=20 \mathrm{~m}$, has far less effect than increasing the channel's width to $d=50 \mathrm{~m}$ for a depth $H_{k}=2.0 \mathrm{~m}$. This can be explained by the fact that the influence of near-bottom friction on the speed of barotropic currents in the channel is no longer dominating over the lateral friction along the channel's walls at depths $H_{k} \geq 2.0 \mathrm{~m}$.

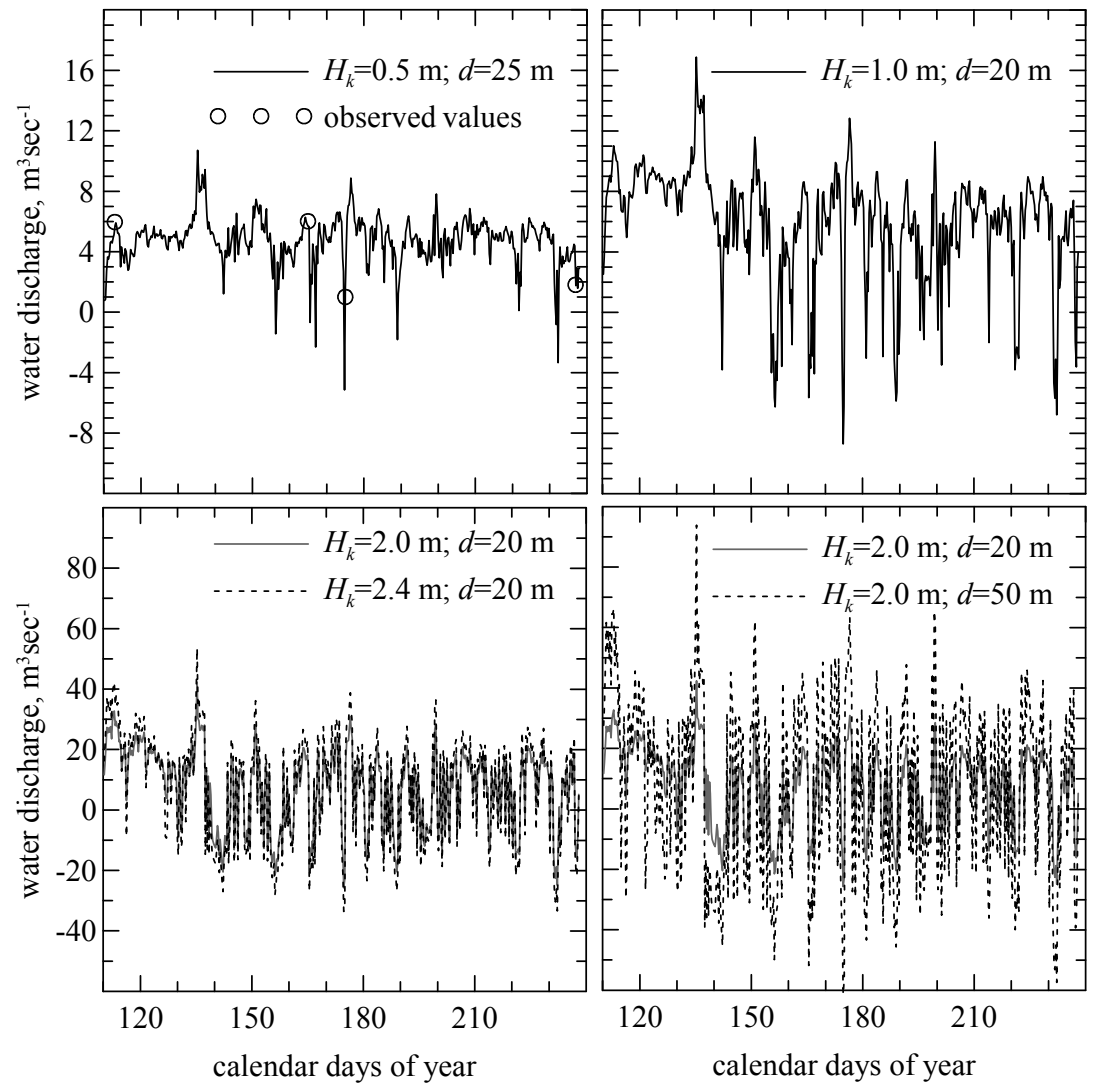

Fig. 2. Variability of water discharge in the «sea-lagoon» connecting channel for different morphometric characteristics ( $H_{k}$ and $d$ are the channel depth and width, respectively). Positive values correspond to water flows from the sea into the lagoon and negative ones to flows from the lagoon into the sea 
Comparing the fluctuations of water level in the sea and the lagoon for different morphometric characteristics of the «sea-lagoon» connecting channel shows that the water level in the lagoon does not reach the sea level for Sets 1 and 2 (Fig. 3). The initial phase of lagoon filling-up results from the substantial difference of initial water levels between the lagoon and the sea $(\Delta \xi=0.25 \mathrm{~m})$ and lasts for about 40 days.

The mean water levels in the liman and the sea become almost equal over 20-25 days for Sets 3 and 4, but 5-10 days for Set 5. The water exchange via the channel then becomes bidirectional and is controlled by wind-induced oscillations of water level (denivellation) in the sea and the lagoon.

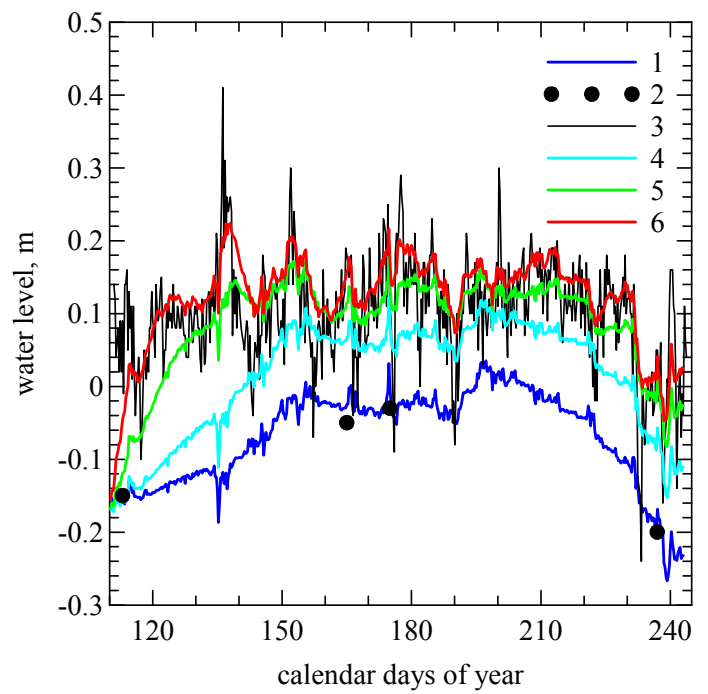

Fig. 3. Water level in the sea and in the lagoon from an initial unperturbed state for different morphometric characteristics of the connecting channel: $1-H_{k}=0.5 \mathrm{~m}, d=25 \mathrm{~m} ; 2-$ observed values in the lagoon at $H_{k}=0.5 \mathrm{~m}, d=25 \mathrm{~m} ; 3$ - observed values in the sea; $4-H_{k}=1.0 \mathrm{~m}, d=20 \mathrm{~m}$; $5-H_{k}=2.0 \mathrm{~m}, d=20 \mathrm{~m} ; 6-H_{k}=2.0 \mathrm{~m}, d=50 \mathrm{~m}$

The influence of different morphometric characteristics of the «sea-lagoon» connecting channel on water renewal in different parts of the lagoon (Fig. 4) was analyzed at four selected reference points in the lagoon's water area. Point P1 is located in the southern part of the lagoon and was the closest one to the channel. Point P2 is located at the southern border of the lagoon's central part and point P3 in its center. The deep hollows in the southern and central parts of the lagoon are separated by a relatively shallow region (up to $4 \mathrm{~m}$ deep), which is the underwater prolongation of the coastal spit. Point P4 is located in the shallow-watered northern part of the lagoon. Previous works $[16,20]$ examined the features of barotropic water circulations in Tyligulskyi Liman lagoon and concluded that the water exchange between its southern, central and northern parts was hampered. This was due the particular geomorphological characteristics of the lagoon (shoreline configuration, depths pattern along the lagoon, presence of shallow water spits).

Using a conservative admixture of neutral buoyancy as a tracer of seawater intrusion into the lagoon and of water renewal in its different zones (Fig. 4) has showed:

1. For the morphometric characteristics of the channel before its reconstruction (Set 1), the percentage contribution of seawater to the total water volume at the end of the calculation period reached the following values: P1 - $23 \%$; P2 - 12\%; P3 - 6.5\%; P4 - 1.5\%. After channel opening, the lag-time of seawater to reach points $\mathrm{P} 3$ and $\mathrm{P} 4$ was $\sim 30$ days and 60 days, respectively.

2. The percentage of seawater would raise to values P1 - $30 \%$; P2 - $18 \%$; P3 $-10.5 \%$; $\mathrm{P} 4-3.5 \%$ in case of realization of Set 3 and to values P1 - 38\%; P2 - 23\%; P3 - $14 \%$; P4 - $5 \%$ for Set 5. The lag-time for the transformed seawater to reach points P3 and P4 would reduce to 15 and 40 days, respectively. 
3. For whole lagoon, the speed of its water renewal would increase 1.4-1.5 fold in case of realization of Sets 3, 4 and 1.9 for the Set 5 if the functioning period of the channel remains the same.
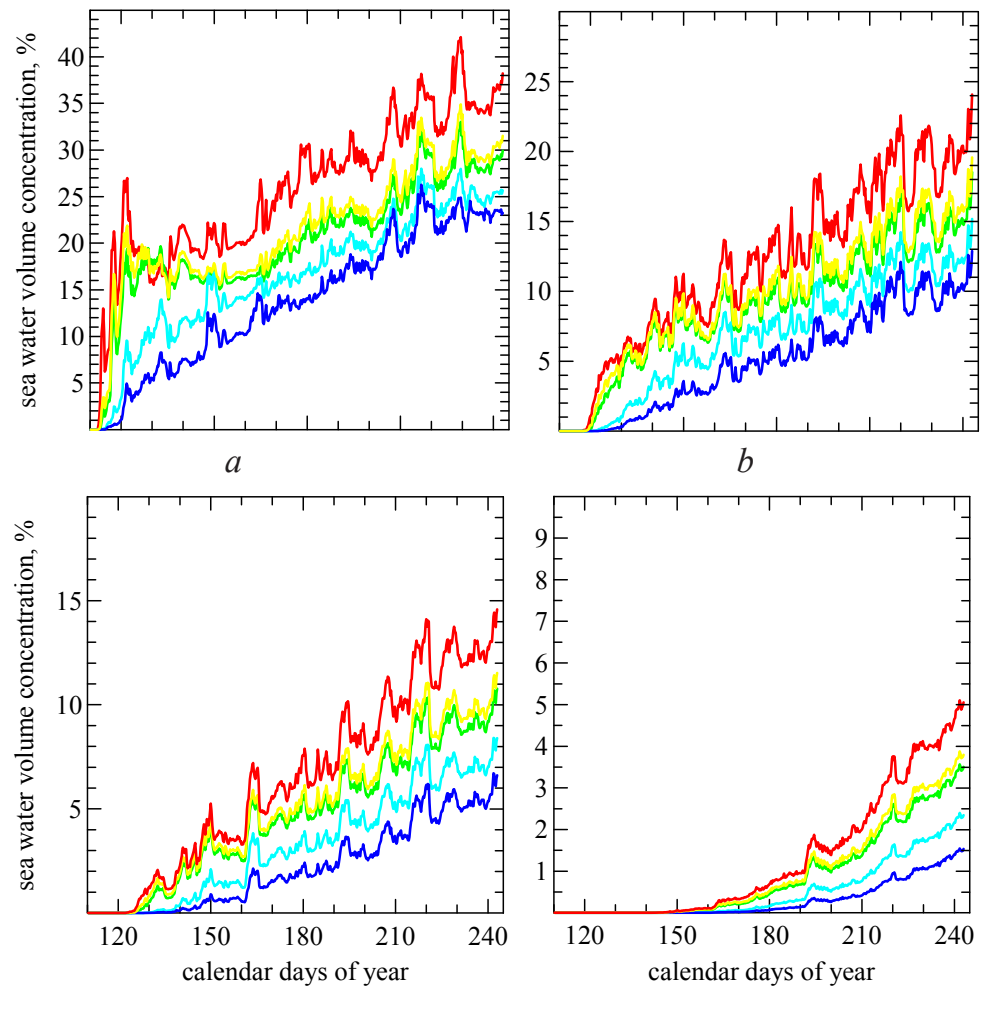

c

$d$

Fig. 4. Sea water volume concentration (\%) at the reference points in the lagoon:

$a-\mathrm{P} 1 ; b-\mathrm{P} 2 ; c-\mathrm{P} 3 ; d-\mathrm{P} 4$. The morphometric characteristics of connecting channel are: $1-H_{k}=0.5 \mathrm{~m}, d=25 \mathrm{~m} ; 2-H_{k}=1.0 \mathrm{~m}, d=20 \mathrm{~m} ; 3-H_{k}=2.0 \mathrm{~m}, d=20 \mathrm{~m} ; 4-H_{k}=2.4 \mathrm{~m}, d=20 \mathrm{~m}$;

$$
5-H_{k}=2.0 \mathrm{~m}, d=50 \mathrm{~m}
$$

\section{Discussion}

The above results allow concluding that if the channel is operating permanently during the 132 days then even in southern part of the lagoon abutted on the channel its water is only partly renewed by the sea water. After the channel closes owing to blocking it with sandy sediments from the sea side, the inflown previously sea water will continue to mix with the lagoon water. During the next 7-8 months, until the channel will be forcingly opened in April of the next year, the sea water will redistribute in the lagoon. It is obvious that during this time period, as a result of advective transfer and turbulent mixing, the concentrations of conservative admixture of neutral buoyancy will equalize in all parts of the lagoon. In the other words, the sea water volume concentration at all points of the lagoon will be equal to some mean value, which can be estimated as follows

$$
C_{s r}=\frac{\sum_{i, j, k} C_{i, j, k} W_{i, j, k}}{\sum_{i, j, k} W_{i, j, k}},
$$

where $C_{i, j, k}$ is the concentration of admixture in the points of three-dimensional computational grid at the end of computation before the termination of water exchange between the lagoon and the sea; $W_{i, j, k}$ is the elementary volume of each cell of the computational grid limited by the lagoon's water surface; $C_{s r}$ is the mean concentration of admixture in the lagoon, which will be 
established at all points of computational grid in the lagoon, before the water exchange between the lagoon and the sea will restore in the following year.

By using Eq. (2), the mean volume concentrations of the sea water incoming into the lagoon $\left(C_{s r}\right)$ for sets 1,3 , and 5 are $10.7,15.63$, and $20.25 \%$, respectively. As the full renewal of the lagoon water by sea water corresponds to $C_{s r}=100 \%$, the time during which this full renewal will be reached is 9.3 years for the Set 1, 6.5 years for the Set 3, and 4.94 years for the Set 5 .

Therefore, the time for the full water renewal of Tyligulskyi Liman by the seawater will be at least 5 to 6.5 years even if the scenarios considered in Section 4 will be realized but the operational regime of the channel is maintained. This feature distinguishes the Tyligulskyi Liman lagoon from those considered earlier [7, 8, 21, 22]. It is obvious that for a more significant reduction of water renewal time in the lagoon, it is necessary to provide the permanent water exchange between the lagoon and the sea during the whole year. Also, it is necessary to protect the connecting channel from the sandy sedimentation from the sea side. This task has been considered in [23].

Concluding from the above, the numerical hydrodynamic modelling allows estimating the influence of morphometric characteristics of the connecting channel on the intensity of water exchange of Tyligulskyi Liman lagoon with the sea and on water renewal in the various zones of the lagoon. Prior to the beginning of its reconstruction, the «sea-lagoon» connecting channel ensured only the replenishment of the lagoon with seawater to compensate for the deficit in the annual freshwater balance. Under such circumstances, the lagoon behaved as a stagnant reservoir, accumulating the salts carried by the inflowing seawater and exhibiting a gradual increase in salinity and eutrophication. The time of full water renewal in the lagoon by the seawater has exceeded the 9 years.

At the width of $20 \mathrm{~m}$, deepening of the connecting channel up to $2 \mathrm{~m}$ will ensure a bidirectional water exchange between the lagoon and the sea under the influence of wind-induced fluctuations in water levels of both the lagoon and the sea. These conditions will partially remove the accumulated stocks of salts, nutrients and organic matter from the lagoon; i. e. flushing of the lagoon would occur. The time of full water renewal in the lagoon by the seawater will decrease to the 6.5 years.

Increasing the channel's depth to more than $2 \mathrm{~m}$ while preserving the $20 \mathrm{~m}$ width will not be effective, because the near-bottom friction has little effect on the speed of barotropic current at these channel's depths. On the other hand, increasing width up to $50 \mathrm{~m}$ for a depth of $2 \mathrm{~m}$ will intensify the bidirectional water exchange via the channel. The time of full water renewal in the lagoon by the seawater will consequently decrease to the 5 years. However, implementation of this set is connected with impediments such as additional withdrawal of territories for channel construction from the Tyligulskyi Regional Landscape Park (protected under the Ramsar Convention). Another significant increase in financial expenses is associated with the reconstruction of the highway bridge crossing over the channel in addition to deepening and widening of the channel.

Due to both the channel and the lagoon are significantly elongated in the meridional direction and the channel has a low capacity, the sea water slowly inflows into the lagoon. If the above scenarios for the reconstruction of the channel will be implemented, an increase of water exchange with the sea can significantly affect the environmental conditions during the algae vegetation period (from March to September). However, this is a case for the southern part of the lagoon only. Nevertheless, in the long-term, the channel's reconstruction could favor the relative stabilization of the hydroecological regime of the lagoon as a result of its partial flushing.

In order to decrease the time of water renewal in the lagoon by the seawater and to intensify the flushing of the lagoon, the possibility providing permanent operation of the channel during the whole year should be examined in addition to the considered scenarios for its reconstruction. This will be the subject of further research by the authors.

Coastal lagoons occupy $13 \%$ of the coastal areas of the oceans. For example, about 400 lagoons are located only on the Mediterranean coast [24]. Among the coastal lagoons, the choked lagoons [4] located in the zones of the sea coast with arid and semi-arid climate are the most environmentally problematic. In those zones, evaporation from the water surface is comparable to or prevails precipitation and freshwater inflow from the catchment. These lagoons usually have low 
flushing rate due to limited water exchange with the sea that contributes to high primary production rate, eutrophication, accumulation of salt and pollutants. Due to climatic changes observed in recent decades and expected in the future, evaporation from the water surface of these lagoons increases and the freshwater inflow decreases. Under these circumstances, intensifying water exchange with the sea is a particular solution to the problem of stabilizing environmental conditions and preserving natural resources in these lagoons. Therefore, a proper hydraulic management through human intervention, which helps controlling and maintaining the ecological characteristics of lagoons, is more important than ever [24].

The used methodological approach allows determining the extent of seawater intrusion into the "choked" lagoon during its connection with the sea under various conditions of water exchange and, consequently, assessing possible influence of the seawater on ecosystem processes in various parts of the lagoon. The proposed simplified method for estimating the time of full water renewal in large "choked" lagoons allows avoiding multi-year modelling. This method allows determining the relative effectiveness of different approaches for hydraulic management aimed at enhancing water exchange with the sea, e. g. by building new or reconstructing existing channels connecting the lagoon with the sea.

\section{Conclusions}

The conservative admixture of neutral buoyancy was used as an indicator of sea-water intrusion into the lagoon in the hydrodynamic modelling. This allowed estimating the time of full water renewal in the lagoon before and after the reconstruction of connecting channel between the lagoon with the sea.

The methodical approach is proposed for estimating a time of total water renewal of elongated 'closed' non-tidal lagoons and can be used for other similar coastal lagoons. The water exchange of these lagoons with the sea is forced by morphometric characteristics of channels with limited water inflow and last for many years. In this approach, the sea water inflow into the lagoon is simulated using the hydrodynamic model only during the period of the canal functioning within the year. And then, using these results, the number of years is estimated, during which the total renewal by sea waters will occur of the lagoon.

Before the reconstruction of the connecting sea-lagoon channel, it provided only replenishment of the lagoon with sea water to compensate the deficit in the annual fresh balance. At the same time, the lagoon remained a stagnant water body, which led to the accumulation of salt coming together with the sea waters. The full water renewal time of the lagoon was more 9 years.

The reconstruction of the channel with increasing the depth to $2 \mathrm{~m}$ and maintaining width of $20 \mathrm{~m}$ will reduce the time of full water renewal of the lagoon by sea waters to 6.5 years. Its implementation will contribute to the partial removal of accumulated salts, biogenic substances, and organic matter from the lagoon. Increasing the channel width up to $50 \mathrm{~m}$ would reduce the time of full water renewal of the lagoon by sea waters up to 5 years. However, this option is not relevant presently due to the problems associated with its practical implementation indicated in the previous section.

\section{References}

[1] Gönenç, I. E., Wolflin, J. P. (Eds.) (2004). Coastal Lagoons: Ecosystem Processes and Modeling for Sustainable Use and Development. Boca Raton, FL: CRC Press, 528. doi: https://doi.org/10.1201/9780203493328

[2] Newton, A., Brito, A. C., Icely, J. D., Derolez, V., Clara, I., Angus, S. et. al. (2018). Assessing, quantifying and valuing the ecosystem services of coastal lagoons. Journal for Nature Conservation, 44, 50-65. doi: https://doi.org/10.1016/j.jnc.2018.02.009

[3] Zaitsev, Y. P., Aleksandrov, B. G., Minicheva, G. (2006). The North-Western Part of the Black Sea: Biology and Ecology. Kyiv: Naukova Dumka.

[4] Kjerfve, B. (1994). Chapter 1 Coastal Lagoons. Elsevier Oceanography Series, 1-8. doi: https://doi.org/10.1016/s04229894(08)70006-0

[5] Grebin, V. V. (2010). The Current Water Conditions of Ukrainian Rivers (Landscape-Hydrological Analysis). Kyiv: Nika-Center.

[6] Loboda, N., Bozhok, Y. (2015). Impact of climate change on water resources of North-Western Black Sea region. International Journal of Research in Earth and Environmental Sciences, 2 (9), 1-6. 
[7] Umgiesser, G., Ferrarin, C., Cucco, A., De Pascalis, F., Bellafiore, D., Ghezzo, M., Bajo, M. (2014). Comparative hydrodynamics of 10 Mediterranean lagoons by means of numerical modeling. Journal of Geophysical Research: Oceans, 119 (4), 2212-2226. doi: https://doi.org/10.1002/2013jc009512

[8] Fiandrino, A., Ouisse, V., Dumas, F., Lagarde, F., Pete, R., Malet, N. et. al. (2017). Spatial patterns in coastal lagoons related to the hydrodynamics of seawater intrusion. Marine Pollution Bulletin, 119 (1), 132-144. doi: https://doi.org/10.1016/j.marpolbul.2017.03.006

[9] Tuchkovenko, Y., Loboda, N., Khokhlov, V. (2015). The Physio-Geographical Background and Ecology of Tyligulskyi Liman Lagoon. Coastal Lagoons in Europe: Integrated Water Resource Strategies. London, UK: IWA Publishing. 77-85.

[10] Tuchkovenko, Y. S., Loboda, N. S. (2014). Water Resources and Hydro-Ecological Regime of the Tyligulskyi Liman Lagoon. Odessa: Odessa State Environmental University.

[11] Gubanova, O., Tuchkovenko, Y., Khokhlov, V., Stepanenko, V., Baggett, S. (2015). The Management Story of Tyligulskyi Liman Lagoon. Coastal Lagoons in Europe: Integrated Water Resource Strategies. London, UK: IWA Publishing, 87-96.

[12] Dolbeth, M., Stålnacke, P., Alves, F. L., Sousa, L. P., Gooch, G. D., Khokhlov, V. et. al. (2016). An integrated Pan-European perspective on coastal Lagoons management through a mosaic-DPSIR approach. Scientific Reports, 6 (1). doi: https://oi.org/ 10.1038/srep19400

[13] Lillebø, A. I., Somma, F., Norén, K., Gonçalves, J., Alves, M. F., Ballarini, E. et. al. (2016). Assessment of marine ecosystem services indicators: Experiences and lessons learned from 14 European case studies. Integrated Environmental Assessment and Management, 12 (4), 726-734. doi: https://doi.org/10.1002/ieam.1782

[14] Hess, K. W. (1989). MECCA Programs Documentation. NOAA Technical Report NESDIS 46. Washington, DC.

[15] Hess, K. (2000). MECCA2 Program Documentation. NOAA Technical Report NOS CS 5. Silver Spring, MD.

[16] Tuchkovenko, Yu. S., Ivanov, V. A., Tuchkovenko, O. A. (2012). Modelling of water exchange of Tiligulsky liman-lagoon with the Black Sea. Marine Hydrophysical Journal, 5, 42-58.

[17] Note on the calculation of evaporation from the surface of water bodies (1969). Leningrad: Gidrometeoizdat.

[18] Panin, G. N., Brezgunov, V. S. (2007). Influence of the salinity of water on its evaporation. Izvestiya, Atmospheric and Oceanic Physics, 43 (5), 663-665. doi: https://doi.org/10.1134/s0001433807050143

[19] Integrated water resources and coastal zone management in European lagoons in the context of climate change. URL: http://lagoons.biologiaatua.net/

[20] Tuchkovenko, Yu. S., Kushnir, D. (2013). Modeling of wind-driven circulation of water in the Tiligul estuary. Bulletin of Odessa State Environmental University, 16, 149-158.

[21] Dinu, I., Umgiesser, G., Bajo, M., De Pascalis, F., Stănică, A., Pop, C. et. al. (2015). Modelling of the response of the Razelm-Sinoe lagoon system to physical forcing. Geo-Eco-Marina, 21, 5-18. URL: https:/www.geoecomar.ro/website/publicatii/ Nr.21-2015/21_01_DINU_2015.pdf

[22] De Brito Jr., A. N., Fragoso Jr., C. R., Larson, M. (2018). Tidal exchange in a choked coastal lagoon: A study of Mundaú Lagoon in northeastern Brazil. Regional Studies in Marine Science, 17, 133-142. doi: https://doi.org/10.1016/j.rsma.2017.12.005

[23] Kushnir, D., Tuchkovenko, Y. (2018). Assessment of effectiveness of coastal protection structures for ensuring a constant lagoon-sea water exchange in the north-western Black Sea region. Geographia Technica, 13 (1), 62-72. doi: https://doi.org/ 10.21163/gt_2018.131.07

[24] Cataudella, S., Crosetti, D., Massa, F. (2015). Mediterranean Coastal Lagoons: Sustainable Management and Interactions among Aquaculture, Capture Fisheries and the Environment. Studies and Reviews. General Fisheries Commission for the Mediterranean. No. 95. Rome: FAO, 293. 